\title{
Nesting Associations without Interdependence: A Preliminary Review on Plesiobiosis in Ants
}

\author{
Orsolya Kanizsai, Gábor Lőrinczi, and László Gallé \\ Department of Ecology, University of Szeged, 52 Közép Fasor, Szeged 6726, Hungary \\ Correspondence should be addressed to Orsolya Kanizsai; orsi.kanizsai@gmail.com
}

Received 6 February 2013; Revised 24 April 2013; Accepted 9 May 2013

Academic Editor: David P. Hughes

Copyright (C) 2013 Orsolya Kanizsai et al. This is an open access article distributed under the Creative Commons Attribution License, which permits unrestricted use, distribution, and reproduction in any medium, provided the original work is properly cited.

\begin{abstract}
Plesiobiosis, the most basic form of interspecific associations in ants, denotes occasional or regular nesting of heterospecific colonies of certain species pairs in close proximity to each other without biological interdependence. Plesiobionts differ from each other both in morphology and in behaviour (e.g., in their foraging strategies), and at least one of the plesiobiotic pair is a submissive species. Recent studies on plesiobiosis have revealed that Formica fusca and Lasius flavus are two of the most frequent plesiobionts. To date, at least 48 different plesiobiotic species pairs have been recorded from various habitat types of the Holarctic region. Two main habitat properties may play a role in the forming of plesiobiosis: the scarcity of suitable nesting sites as a forcing factor and the sufficient amount of food sources available, influencing the abundance of colonies. Thus, high colony density may contribute to the formation of such associations, resulting in (1) frequent nesting in each other's neighbourhood and (2) stronger intraspecific competition, which forces colonies into the vicinity of heterospecific nests. Plesiobiotic associations formed this way may promote persistent coexistence, leading to the formation of other types of interspecific associations (e.g., clepto- or lestobiosis).
\end{abstract}

\section{Introduction}

Various types of interspecific associations exist among ant species. These can be categorised on the basis of the degree of interactions between heterospecific colonies, ranging from simple cooccurrence with loose interaction to highly specialised social parasitism [1-3]. Following the suggestion by Wasmann [4] and Wheeler [5], Hölldobler and Wilson [6] distinguished two main types of associations between ant colonies, namely, "compound nests" and "mixed nests." Associations belonging to "mixed nests" mostly result from social parasitism, where one of the species (as a social parasite) depends on its partner, which represents the host. On the other hand, the association types of "compound nests" differ from each other in the degree of interspecific relations ranging from neutral associations through mutualism and commensalism to typical parasitism.

The vast majority of studies on interspecific associations in ants have focused on the forms of typical social parasitism (i.e., temporary parasitism, slavery, and inquilinism) $[1,3$, 7-9] or on associations that belong to "compound nests" representing a higher degree of biological interdependence between heterospecific colonies (i.e., cleptobiosis, lestobiosis, xenobiosis, or parabiosis) ([10-20] etc.). However, few studies have dealt with plesiobiotic associations so far, and most of these reported only observations that might indicate the existence of such associations $[5,21-36]$.

Although numerous classifications exist for associations related to "compound nests" $[2,4-6,22,37]$, most of them are based on relatively few reports [2]. According to each of the classification systems, plesiobiosis is the most rudimentary form of heterospecific associations. This type of association occurs between species pairs that differ from each other in morphology, in behaviour, and in taxonomy, and it denotes nesting close to each other without biological interdependence. Owing to this close proximity, plesiobiotic partners share not only the nesting shelter, but the same microhabitat, and possibly the foraging area as well.

In this review our aim was to summarise the existing information on plesiobiosis, by listing and discussing (1) the recorded plesiobionts and plesiobiotic partner species and (2) the assumed background factors that may promote 
the formation and persistence of plesiobiotic associations. Furthermore, we pose open questions to call attention to the importance of collecting data considering the mentioned ecological approaches.

\section{General Categorization of Interspecific Associations in Ants}

The general classification system of "compound nests" includes five different association types with increasing degree of interactions and biological interdependence between the associated heterospecific colonies. As mentioned above, the most basic form of these associations is plesiobiosis $[5,6,22]$. According to the classical definition, plesiobiotic partner colonies share the same microhabitat without further interactions $[1,5]$. In the case of cleptobiosis and lestobiosis, one of the associated colonies gains benefit from being in the vicinity of the other colony. This can be through robbing the stored resources of the other colony, stealing food from returning foragers (cleptobiosis), or preying on the brood of the alien colony (lestobiosis), thereby reducing the costs of searching and handling of food $[1,6,9,10]$. Parabiosis differs from the other types of "compound nests" since it is a mutualistic relationship between the associated colonies [1, 6]. In these cases, each species gains benefit from its partner (e.g., by protection from enemies or competitors, interspecific trail following, etc.), and these benefits overweigh the costs of the maintenance of the coexistence [11]. Although xenobiosis is considered as a type of "compound nests", it has more social parasitic features than the previous ones. Xenobiotic species (i.e., "guest ants") spend their life inside the nest of their host colony stealing food or inducing trophallaxis with host workers [9]; therefore, xenobiosis is a truly parasitic form of interspecific associations $[1,6,9]$.

In typical social parasitic associations, individuals of different colonies mix inside the nest, and heterospecific brood is mostly cared for by host workers. These associations imply biological interdependence; that is, the parasite always depends on its host(s) [9]. The queens of temporary social parasitic species use their host colonies during colony foundation, and the mixed colony gradually develops to a pure, monospecific colony of the parasitic species [1]. In this case, the parasitic species depends on its host only during colony foundation $[1,6,9,12]$. Unlike temporary social parasitism, slave-maker species depend on their hosts throughout their lives; that is, they are constrained to renew their labour force through robbing brood from host colonies in the course of slave-making raids $[1,6,9]$. The final and most extreme stage of social parasitism is inquilinism. Inquilinous species are the "ultimate social parasites," as they spend their entire life cycle inside the nest of their host colony. Most of these species lack the worker caste, and their queens invest their energy to produce only reproductive offspring $[1,6,9]$.

\section{Plesiobiotic Association}

Regarding the lack of biotic interdependence between the associated colonies $[1,5,6,12,30]$, plesiobiosis is considered the most rudimentary form of interspecific associations in ants. This relationship denotes the nesting of mostly two colonies of different species in the direct proximity of each other, which means that the plesiobiotic colonies occupy the same nesting shelter (e.g., in or under logs, stumps, rocks, etc.). On the basis of the currently available data on plesiobiotic associations, this close nesting can occur occasionally or regularly, depending on the species and/or habitat type (as discussed below). Although plesiobiotic nests are adjacent to one another in several cases, they always remain separate as individual units, and the members of heterospecific colonies do not mix [6]. Plesiobionts are potentially hostile to each other, and if the nest galleries accidentally break in, fighting and brood theft may occur $[6,28,37]$. As a rule, plesiobiotic partner species differ from each other morphologically (e.g., different body size) and/or behaviourally (e.g., different foraging strategies or competitive ability), and they belong to at least different genera [6]. These differences may promote the coexistence of associated colonies according to the "limiting similarity" hypothesis suggested by MacArthur and Levins [38]. Basically, the less similar the species are the more likely they occur together in a plesiobiotic relationship in order to avoid intraspecific competition.

\section{A Synthesis of the Recorded Cases of Plesiobiosis}

4.1. Plesiobionts and Plesiobiotic Partners. In Table 1, we list 49 species that have been observed so far in plesiobiotic associations. 29 of these belong to the subfamily Formicinae, 17 to Myrmicinae, and only 3 to Ponerinae. The four most frequent genera whose members established plesiobiotic relationships were Formica (11 species), Camponotus (9 species), Lasius (8 species), and Myrmica (4 species), well representing the general number of genera and species in the Holarctic [6].

Recent studies on plesiobiosis revealed that two species, Formica fusca (Linnaeus, 1758) and Lasius flavus (Fabricius, 1782), can be considered as two of the most frequent plesiobionts, on the basis of the total number of their so far known plesiobiotic partner species (Table 1).

Up to the present, at least 48 different plesiobiotic species pairs have been recorded from different habitats of the Holarctic region. Among these, F. fusca was involved in 12 cases (25\%), L. flavus in 8 cases (16.3\%), Monomorium minimum in 5 cases (10.2\%), M. rubra and Myrmecina americana in 4 cases $(8.16 \%)$, respectively, and Pheidole picea and Lasius umbratus in 3 cases $(6.12 \%)$ each (Table 1$)$. The total number of plesiobiotic associations-where the exact number of the observed cases was given-was 69 , from which the two most frequent plesiobionts participated in 46 associations, F. fusca in 28 cases $(60.9 \%)$ and $L$. flavus in 18 cases (39.1\%) (Table 1$)$. F. fusca established plesiobiotic associations with species belonging to 6 different genera of two subfamilies (Myrmicinae and Formicinae). Its typical plesiobiotic partners were Myrmica spp. (M. rubra and M. ruginodis), Tetramorium spp. (T. cf. caespitum), Leptothorax spp. (L. acervorum), Lasius spp. (L. platythorax, L. niger, and L. flavus), and Camponotus spp. (C. vagus and $C$. herculeanus). Plesiobiotic partners of L. flavus belonged to 3 different genera, Formica spp. (F. fusca, F. cunicularia, F. fuscocinerea, and F. aquilonia), 


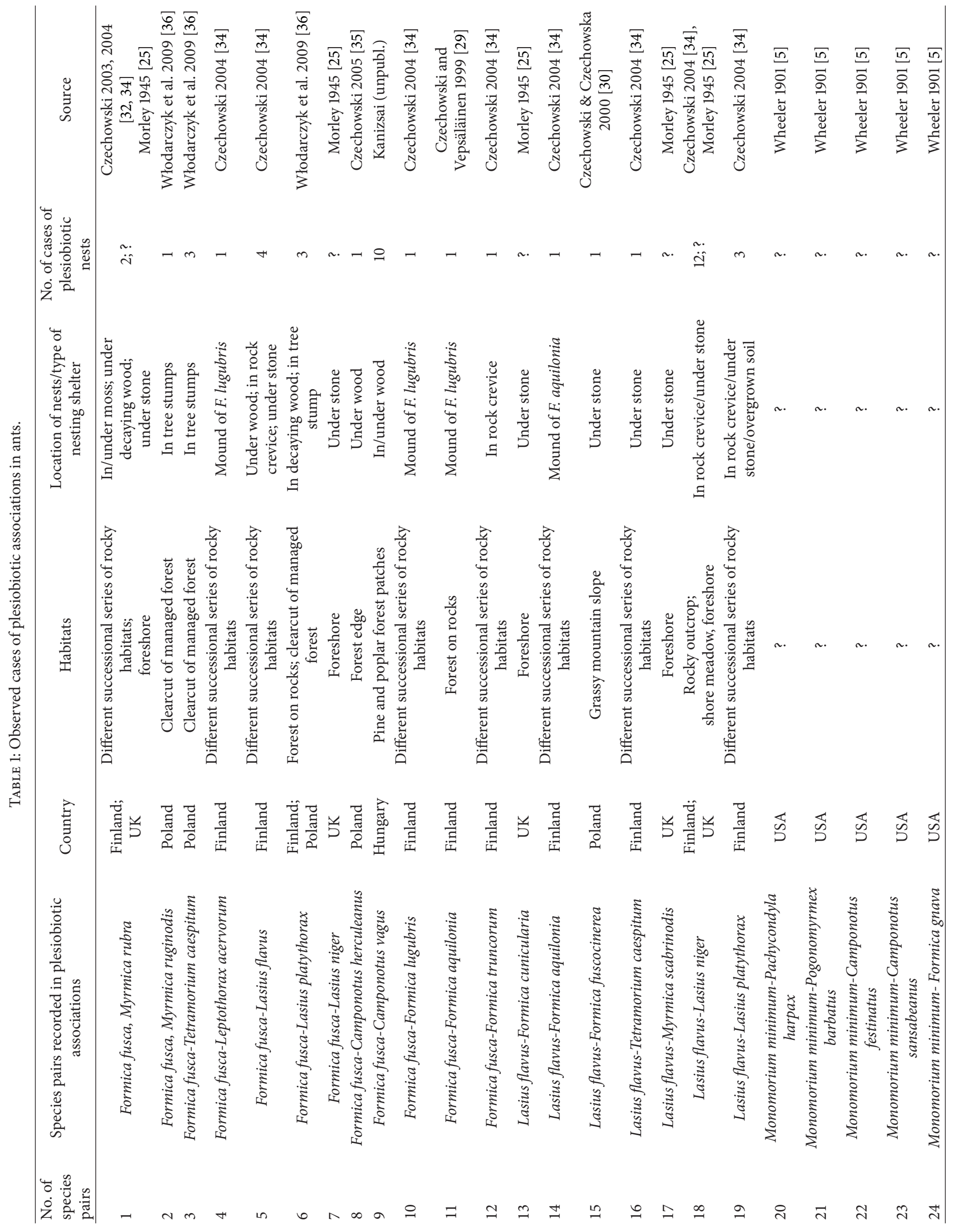




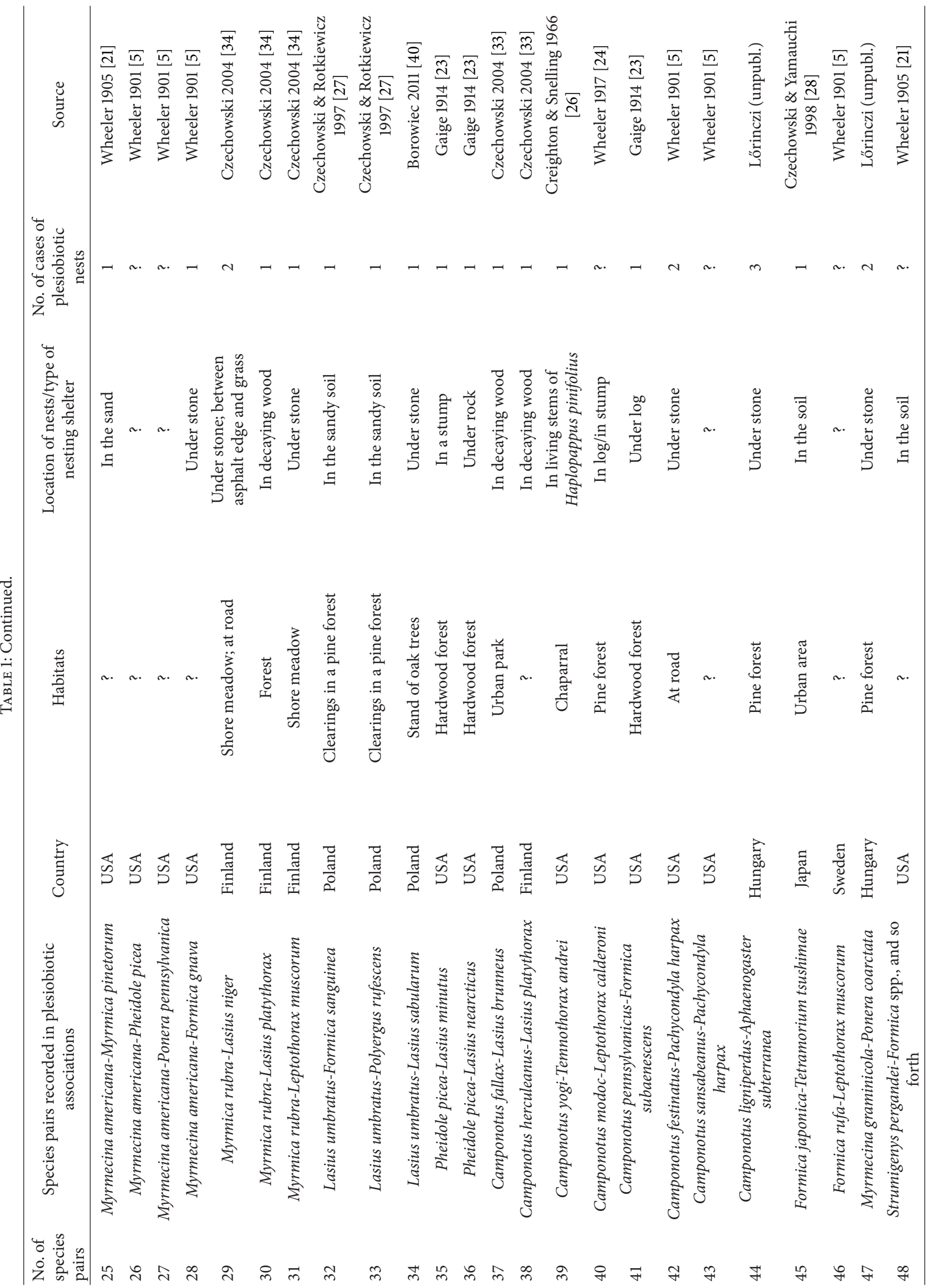


Tetramorium spp. (T. cf. caespitum), and interestingly other members of the genus Lasius (L. niger and L. platythorax).

Although plesiobiotic partners usually belong to at least different genera, both F. fusca and L. flavus occurred in plesiobiosis with species of the same genera. These untypical associations were, however, mostly formed between species of different subgenera with different behavioural features. There was only one exception to this rule in which two species from the subgenus Chthonolasius, namely, Lasius umbratus and Lasius sabularum occurred in each other's close proximity, although the exact nature of this association is unknown [40]. Among the untypical plesiobiotic associations, the ones between F. fusca and wood ants (Formica lugubris, F. aquilonia, and F. truncorum) were the most peculiar cases considering the well known temporary social parasitic character of wood ants, whose young queens often use $F$. fusca as host for colony foundation [6]. Nevertheless, in one case F. fusca was observed to move into an uninhabited part of the nest mound of a F. aquilonia colony, which was possibly queenless, though this $F$. fusca colony still remained there after the reviving of the wood ants [29].

\subsection{Background Factors and Driving Forces of Plesiobiosis}

4.2.1. Role of Habitat Type and Food Supply. Plesiobiotic nests have been recorded from various habitat types, representing different stages of both primary succession and secondary succession. It is important to note, however, that a number of records on plesiobiosis were mere observations without any significant ecological information, for example, on habitat type, nesting site, and/or the number of observed cases of plesiobiotic pairs.

Many of the recorded plesiobiotic species pairs have been described in rocky habitats in Finland. The spectrum of study sites ranged from earlier stages of primary succession, such as open rocky outcrops and shore meadows, to mature pine forests, which represented the last successional stage of rocky habitats. According to this study, most of the plesiobiotic associations involving Lasius s. str. were observed in earlier stages of primary succession. This observation confirmed the hypothesis by Czechowski [31], stating that plesiobiosis is especially frequent in habitats lacking suitable nesting sites, and the scarcity of these is one of the main factors promoting the formation of plesiobiotic associations between ant colonies [34].

Another investigation was conducted in a sand dune complex in Finland, where only one plesiobiotic association was observed, which was between F. fusca and M. rubra [32]. The reason for this may be that each successional stage of the sand dunes represents more homogenous habitats and larger areas optimal for nesting than rocky habitats [32].

Species that prefer to inhabit stumps can be suitable objects for studying the effect of the amount of potential nesting sites on the frequency of plesiobiotic associations. Włodarczyk et al. [36], for instance, studied clearcuts in a managed forest in western Poland, where stumps that were left on clearcuts served as suitable nesting sites for several species. Although clearcuts represented the initial stage of secondary succession, the amount of potential nesting sites for ants preferring stumps was relatively high, and almost half of the available stumps were occupied by colonies of 9 different ant species [36]. Of the 512 stumps that were checked, five were inhabited by more than one ant species, representing plesiobiotic associations, with F. fusca as one of the partners in all cases ( $F$. fusca, Tetramorium caespitum in three cases; F. fusca, Myrmica ruginodis in one case and F. fusca, L. platythorax in one case) [36]. Although clearcuts offered a high number of stumps suitable for nesting, the sparse vegetation cover provided poor trophic conditions for aphid-related ant species compared with forest patches [36], resulting in the presence of fewer species competing for the available nesting sites.

Investigations on plesiobiosis between F. fusca and C. vagus were conducted in patches of pine and poplar forests in central Hungary (Kanizsai, unpubl.). It was shown that both the density of nests and the number of plesiobiotic associations were influenced by the age of forest patches, and there were more plesiobiotic relationships in older patches than in younger ones. A possible explanation can be that the higher nest density of either species may have facilitated the formation of plesiobiotic associations in older patches.

4.2.2. Role of Nest Density and Intraspecific Competition. Two main habitat properties may contribute to the formation of plesiobiotic associations: the scarcity of suitable nesting sites as a forcing factor [34] and the sufficient amount of food sources available, which significantly influence the abundance and reproductivity of ant colonies [41]. When colony density is high, the depletion of food resources by neighbouring colonies may be more intensive, resulting in an increased mortality, especially in the case of incipient colonies [42]. According to former studies ([43] and references therein), the spacing pattern of the nests of F. fusca and L. flavus (the two most frequent plesiobionts) was, or tended to be regular, when the density of their colonies were high in a suitable habitat. Although competition can produce any type of spacing pattern [44], the regular spatial arrangement of conspecific nests may indicate an intensive intraspecific competition for the same resources [42, 45-49]. Owing to similar food requirements, intraspecific competition supposed to be stronger than interspecific competition [43, 48-50]. The regular dispersion of conspecific nests can reduce the overlapping of foraging areas, thereby minimising intraspecific competition $[43,46,49]$. To effectively utilise foraging areas, it can be advantageous in these cases to maximise the distance between conspecific colonies with similar food requirements and foraging ranges [48]. Thus, it is more favourable for colonies if their nearest neighbours are rather heterospecifics with less overlapping requirements, resulting in a kind of "dear enemy" effect. Therefore, strong intraspecific competition can also contribute to the formation of plesiobiotic associations.

\subsubsection{Significance of Differences between Plesiobiotic Partners}

Potential Role of Competition: Position of the Plesiobionts in the Interspecific Competitive Hierarchy. Recent studies have 
revealed that F. fusca is one of the most frequent plesiobionts among the studied ants. Similarly to other common plesiobionts, F. fusca is also a submissive species in the three-level classification of the competitive hierarchy in ants $[51,52]$. The submissive behaviour and the opportunistic character of this species can be considered as one of the main features that contribute to its frequent cooccurrence with other species in plesiobiotic associations. Although most of the plesiobiotic partners of $F$. fusca occupied a higher level in the interspecific competition hierarchy, it established plesiobiotic relationships with species that are also submissive (e.g., with M. rubra, L. flavus, and Leptothorax acervorum).

Being also submissive, Myrmica spp. are also able to coexist with aggressive ant species. For example, $M$. ruginodis and M. scabrinodis were observed to shift their foraging to periods with lower temperature. Accordingly, in areas where territorial competitors were also present, they visited baits at night instead [53].

In the case of the subterranean, cryptic species L. flavus, competitive ability may play a less significant role regarding the coexistence with other species. While the two abovementioned plesiobionts are surface foragers, that is, they mostly search for food on or above the ground, the colonies of L. flavus, however, were found to be associated with various species of root aphids [54]. Thus, for subterranean Cautolasius species, the importance of vertical separation in foraging seems more significant than other mechanisms for reducing competition.

Contrary to the afore-mentioned species, several Camponotus species are typically regarded as encounter species that is, they defend not only their nests but the discovered resources as well [51, 52]; therefore only submissive species can be expected to be their plesiobiotic partners.

Conflict Avoidance: Differences in the Foraging Strategy of Plesiobiotic Partners and Resource Partitioning. As plesiobiotic partner colonies share the same microhabitat [1], they have overlapping foraging area and home ranges owing to the small distances between their associated nests. Accordingly, the probability of an encounter between the members of the two colonies increases as the distance between their nests decreases [55]. Due to the close neighbourhood of the associated colonies, they are expected to interact most intensely with each other. A common outcome of interspecific competition is the minimising of spatial and/or temporal overlapping during foraging, that is, differing from each other in their daily and/or seasonal activity, foraging area, or diet [56-59]. Beside partitioning spatially and/or temporally, different foraging strategies (e.g., individual searching, tandem running and other types of recruitment systems) may also contribute to the coexistence of different species $[39,60,61]$. Although body size can also influence the foraging range, the existence of food recruitment systems makes ants less constrained by their morphology than what can be seen in the case of other animals $[60,62,63]$; thereby, the effects of behavioural features seem more important than those of morphological ones. On the other hand, differences in body size can promote resource partitioning by reducing the overlap in resource use [64]. Although differences in body size cannot explain food-resource partitioning alone, these can still contribute to the formation of a number of plesiobiotic relationships.

\section{Conclusions}

On the basis of the above considerations, we define plesiobiosis as the occasional or regular nesting of heterospecific colonies of certain species in close proximity to each other without biological interdependence.

Based on the currently available data, members of the subfamily Formicinae establish plesiobiotic relationships the most frequently, and the most common plesiobionts among them seems to be F. fusca. The opportunistic and submissive behaviour of this species makes it a typical plesiobiont, and it is also a frequent host of both temporary social parasites and slave makers $[6,65]$.

As a rule, plesiobiosis can be formed between ant species that differ from each other in behaviour-primarily in their competitive ability - and in foraging strategies. Other subordinate species with different behaviour or species with higher competitive ability can also be potential partners as plesiobionts.

Beside the lack of suitable nesting sites, the appropriate amount of available food sources may also play a role in the formation of plesiobiosis, contributing to higher colony densities. The overlap in diet can enhance intraspecific competition, which may force colonies into the vicinity of heterospecific nests. Owing to higher colony density, nesting in each other's close neighbourhood will also occur more frequently. Plesiobiotic associations formed this way may promote a persistent coexistence in cases where the differences are considerable between the partners, which can lead to the formation of other types of interspecific associations with higher levels of biotic interactions.

It is important to note, that the currently available data concerning plesiobiosis are far from being representative. Only a couple of studies have dealt with this topic, and these are restricted to a small number of habitat types of few countries in the northern latitudes. Moreover, most of these studies reported only observations of plesiobiotic cases without additional ecological information, like the regularity of such associations between the species in question. Therefore, to get a more comprehensive picture about plesiobiosis, it would be essential to collect more and detailed data globally.

\section{Open Questions}

Regarding our present knowledge on plesiobiosis in ants, there are still many open questions that need to be answered, which are important for a better understanding of this kind of interspecific relationship.

(1) Persistence of plesiobiosis. Plesiobiosis can be formed occasionally between heterospecific colonies, but we still do not know how persistent these associations are. Although ant colonies have typically been treated as spatially fixed entities, inhabiting a given nesting site permanently, it seems that periodic nest relocation is an important aspect of the behaviour of 
many ant species [66-68]. It is also uncertain what effects may trigger the disaggregation of plesiobiotic colonies and force the relocation of one of the associated plesiobionts.

(2) The role of nesting shelters and "ecosystem engineering." It also provides a basis for further investigation, to what extent the type of nesting shelters (e.g., logs, stumps, and rocks) promotes the formation of plesiobiotic associations and how the already established colonies facilitate the settlement of colonies due to their nest constructions. In temperate regions, a large number of species occupy dead logs and stumps or nest in the soil under rocks [6]. Due to their thermal properties, colonies occupying these shelters are allowed to enter to colony growth stage earlier and they are less vulnerable to unsuitable humidity and temperature values. These beneficial conditions can lead to the joint nesting of two or more species in or under the same shelter, especially if the number of suitable nesting sites is low. For example, the nest mounds of wood ants may provide suitable nesting sites for other species owing to their unique microhabitat conditions [69]. This may serve as an explanation for the untypical plesiobiotic associations observed between $F$. fusca and the members of Formica s. str., where the former species frequently settles into the uninhabited parts of the nest mounds of wood ants [29]. Similarly, many Camponotus species create their nest galleries in trunks and stumps [70-72], which may promote the establishment of colonies of other species in these microhabitats. Owing to this "ecosystem engineering," plesiobiotic associations may develop from an occasional to a regular relationship even without direct interactions between the associated colonies.

(3) The "close" proximity of heterospecific colonies. Former definitions of plesiobiosis emphasise the importance of the close proximity of plesiobiotic colonies, though it is not clear how close this proximity should be or whether these colonies should use the same nesting shelter. In Table 1 we listed only those cases where the plesiobiotic colonies occupied the same nest (i.e., they were under the same stone or in the same log). It is a question, however, whether the frequent neighbouring arrangement of the nests of certain species pairs (when their nests do not necessarily border on one another) can be considered as a plesiobiotic relationship.

(4) Plesiobiotic associations of arboreal species. Most of the recorded cases of plesiobiotic associations are between species that inhabit nests located on or under the ground surface. Arboreal species, however, are also known to frequently create their nests in the vicinity of each other on the same tree, as it was, for instance, observed in the case of Camponotus fallax, Lasius brunneus, and Temnothorax affinis [73]. Actually, it was demonstrated that the former two species can occur in a plesiobiotic relationship [33]. It is an interesting question how frequently arboreal species nest in one another's neighbourhood, and to what extent these cases can be considered as plesiobiosis.

\section{Acknowledgments}

The authors thank Jean-Paul Lachaud, Alan Lenoir, and David P. Hughes for giving them the opportunity to review the topic in this paper. They are also grateful to Wojciech
Czechowski, who kindly provided them with his papers in this topic, and to Csaba Tölgyesi for his suggestions on linguistic issues.

\section{References}

[1] A. Lenoir, P. D’Ettorre, C. Errard, and A. Hefetz, "Chemical ecology and social parasitism in ants," Annual Review of Entomology, vol. 46, pp. 573-599, 2001.

[2] E. Kaufmann, A. K. F. Malsch, M. Erle, and U. Maschwitz, "Compound nesting of Strumigenys sp. (Myrmicinae) and Diacamma sp. (Ponerinae), and other nesting symbioses of myrmicine and ponerine ants in Southeast Asia," Insectes Sociaux, vol. 50, no. 1, pp. 88-97, 2003.

[3] M. H. Huang and A. Dornhaus, "A meta-analysis of ant social parasitism: host characteristics of different parasitism types and a test of Emery's rule," Ecological Entomology, vol. 33, no. 5, pp. 589-596, 2008.

[4] E. Wasmann, Die zusammengesetzen Nester und gemischten Kolonien der Ameisen, Aschendorffschen Buchdruckerei, Münster, Germany, 1891.

[5] W. M. Wheeler, "The compound and mixed nests of American ants," The American Naturalist, vol. 35, part 2-3, pp. 513-539, 791-818, 1901.

[6] B. Hölldobler and E. O. Wilson, The Ants, Belknap Press, Cambridge, UK; Harvard University Press, Cambridge, Mass, USA, 1990.

[7] A. Tinaut, F. Ruano, and M. D. Martínez, "Biology, distribution and taxonomic status of the parasitic ants of the Iberian Peninsula (Hymenoptera: Formicidae, Myrmicinae)," Sociobiology, vol. 46, no. 3, pp. 449-489, 2005.

[8] W. Czechowski, “The route of Formica polyctena Först. as a factor promoting emancipation of Formica fusca L. slaves from colonies of Polyergus rufescens (Latr.) (Hymenoptera: Formicidae)," Polish Journal of Ecology, vol. 54, no. 1, pp. 159$162,2006$.

[9] A. Buschinger, "Social parasitism among ants: a review (Hymenoptera: Formicidae)," Myrmecological News, vol. 12, pp. 219-235, 2009.

[10] F. J. Richard, A. Dejean, and J. P. Lachaud, "Sugary food robbing in ants: a case of temporal cleptobiosis," Comptes RendusBiologies, vol. 327, no. 5, pp. 509-517, 2004.

[11] F. Menzel and N. Blüthgen, "Parabiotic associations between tropical ants: equal partnership or parasitic exploitation?" Journal of Animal Ecology, vol. 79, no. 1, pp. 71-81, 2010.

[12] F. Menzel, Mechanisms and adaptive significance of interspecific associations between tropical ant species [Ph.D. thesis], JuliusMaximilans-Universität Würzburg, Würzburg, Germany, 2009.

[13] A. Buschinger, A. Francoeur, and K. Fischer, "Functional monogyny, sexual behaviour, and karyotype of the guest ant, Leptothorax provancheri Emery (Hymenoptera, Formicidae)," Psyche, vol. 87, no. 1-2, pp. 1-12, 1980.

[14] J. Orivel, C. Errard, and A. Dejean, "Ant gardens: interspecific recognition in parabiotic ant species," Behavioral Ecology and Sociobiology, vol. 40, no. 2, pp. 87-93, 1997.

[15] C. Errard, D. Fresneau, J. Heinze, A. Francoeur, and A. Lenoir, "Social organization in the guest-ant Formicoxenus provancheri," Ethology, vol. 103, no. 2, pp. 149-159, 1997.

[16] U. Maschwitz, C. Go, W. H. O. Dorow, A. Buschinger, and R. J. Kohout, "Polyrhachis loweryi (Formicinae): a guest ant 
parasitizing Rhytidoponera sp. (Ponerinae) in Queensland, Australia," Insectes Sociaux, vol. 50, no. 1, pp. 69-76, 2003.

[17] A. Vantaux, A. Dejean, A. Dor, and J. Orivel, "Parasitism versus mutualism in the ant-garden parabiosis between Camponotus femoratus and Crematogaster levior," Insectes Sociaux, vol. 54, no. 1, pp. 95-99, 2007.

[18] F. Menzel, K. E. Linsenmair, and N. Blüthgen, "Selective interspecific tolerance in tropical Crematogaster-Camponotus associations," Animal Behaviour, vol. 75, no. 3, pp. 837-846, 2008.

[19] F. Menzel, T. Schmitt, and N. Blüthgen, "Intraspecific nestmate recognition in two parabiotic ant species: acquired recognition cues and low inter-colony discrimination," Insectes Sociaux, vol. 56, no. 3, pp. 251-260, 2009.

[20] F. Menzel, M. Staab, A. C. Chung, G. Gebauer, and N. Blüthgen, "Trophic ecology of parabiotic ants: do the partners have similar food niches?" Austral Ecology, vol. 37, pp. 537-546, 2011.

[21] W. M. Wheeler, "An annotated list of the ants of New Jersey," Bulletin American Museum of Natural History, vol. 21, pp. 371403, 1905.

[22] W. M. Wheeler, Ants: Their Structure, Development and Behavior, Columbia University Press, New York, NY, USA, 1910.

[23] F. M. Gaige, "Results of the mershon expedition to the Charity Islands, Lake Huron," Occasional Papers of the Museum of Zoology, vol. 5, pp. 1-29, 1914.

[24] W. M. Wheeler, "The mountain ants of Western North America," Proceedings of the American Academy of Arts and Sciences, vol. 52, pp. 457-569, 1917.

[25] D. W. Morley, "Observations on some plesiobiotic colonies of ants (Hymenoptera), with notes on some other mixtobiotic colonies," Proceedings of the Royal Entomological Society of London, vol. 20, pp. 1-4, 1945.

[26] W. M. S. Creighton and R. R. Snelling, "The rediscovery of Camponotus (Myrmaphaenus) yogi Wheeler (Hymenoptera: Formicidae)," Psyche, vol. 73, no. 3, pp. 187-195, 1966.

[27] W. Czechowski and W. Rotkiewicz, "Common activities of female sexuals of Lasius Umbratus (nyl.) and Formica sanguinea Latr. or Polyergus rufescens (Latr.) on nests of the dulotic species (hymenoptera, formicidae)," Annales Zoologici, vol. 47, no. 3-4, pp. 465-467, 1997.

[28] W. Czechowski and K. Yamauchi, "Plesiobiosis of Formica japonica Motsch. and Tetramorium sp. (Hymenoptera: Formicidae)," Annals of the Upper Silesian Museum (Entomology), vol. 8-9, pp. 99-101, 1998.

[29] W. Czechowski and K. Vepsäläinen, "Plesiobiosis between Formica fusca L. and Formica aquilonia Yarr. (Hymenoptera, Formicidae)," Annales Zoologici, vol. 49, no. 1-2, pp. 125-127, 1999.

[30] W. Czechowski and W. Czechowska, "Formica cinerea fuscocinerea For. in the Pieniny Mts, its untypical habitat and plesiobiosis with Lasius flavus (F.) (Hymenoptera, Formicidae)," Fragmenta Faunistica, vol. 43, pp. 131-133, 2000.

[31] W. Czechowski, "Plesiobiosis between Formica fusca L. and wood ants (Hymenoptera, Formicidae) as a sign of nest competition," Przegląd Zoologiczny, vol. 46, pp. 81-86, 2002.

[32] W. Czechowski, "Plesiobiosis between Formica fusca L. and Myrmica rubra (L.) (Hymenoptera, Formicidae)," Przegląd Zoologiczny, vol. 47, pp. 115-118, 2003.

[33] W. Czechowski, "Plesiobiosis between dendrophilous ants: Camponotus fallax (F.) and Lasius brunneus (Latr.) (Hymenoptera, Formicidae)," Przeglad Zoologiczny, vol. 48, pp. 201-205, 2004.
[34] W. Czechowski, "Scarcity of sites suitable for nesting promotes plesiobiosis in ants (Hymenoptera: Formicidae)," Entomologica Fennica, vol. 15, no. 4, pp. 211-218, 2004.

[35] W. Czechowski, "Nest competition between Camponotus vagus (Scopoli, 1763) and Camponotus herculeanus (Linnaeus, 1758) (Hymenoptera: Formicidae) in Białowieża Forest (Poland)," Myrmecologische Nachrichten, vol. 7, pp. 43-45, 2005.

[36] T. Włodarczyk, M. Zmihorski, and A. Olczyk, "Ants inhabiting stumps on clearcuts in managed forest in Western Poland," Entomologica Fennica, vol. 20, no. 2, pp. 121-128, 2009.

[37] E. O. Wilson, The Insect Societies, The Belknap Press of Harvard University, Cambridge, UK, 1971.

[38] R. H. MacArthur and R. Levins, “The limiting similarity, convergence and divergence of coexisting species," The American Naturalist, vol. 101, pp. 377-385, 1967.

[39] O. Kanizsai, "The possible role of the different foraging behaviour of Formica fusca and Camponotus vagus (Hymenoptera: Formicidae) in promoting their plesiobiotic associations," Acta Scientiarum Transylvanica, vol. 20, no. 2, pp. 5-20, 2012.

[40] M. L. Borowiec, "First records of Lasius sabularum (BONDROIT, 1918) in Poland (Hymenoptera: Formicidae)," Myrmecological News, vol. 14, pp. 137-140, 2011.

[41] R. J. Deslippe and R. Savolainen, "Role of food supply in structuring a population of Formica ants," Journal of Animal Ecology, vol. 63, no. 4, pp. 756-764, 1994.

[42] R. T. Ryti and T. J. Case, "Overdispersion of ant colonies: a test of hypotheses," Oecologia, vol. 69, no. 3, pp. 446-453, 1986.

[43] S. C. Levings and J. F. A. Traniello, "Territoriality, nest dispersion, and community structure in ants," Psyche, vol. 88, no. 3-4, pp. 265-319, 1981.

[44] E. S. Adams and W. R. Tschinkel, "Spatial dynamics of colony interactions in young populations of the fire ant Solenopsis invicta," Oecologia, vol. 102, no. 2, pp. 156-163, 1995.

[45] R. A. Bernstein, "Foraging strategies of ants in response to variable food density," Ecology, vol. 56, pp. 213-219, 1975.

[46] R. A. Bernstein and M. Gobbel, "Partitioning of space in communities of ants," Journal of Animal Ecology, vol. 48, pp. 931942, 1979.

[47] S. C. Levings and N. R. Franks, "Patterns of nest dispersion in a tropical ground ant community," Ecology, vol. 63, no. 2, pp. 238-344, 1982.

[48] R. T. Ryti and T. J. Case, "Spatial arrangement and diet overlap between colonies of desert ants," Oecologia, vol. 62, no. 3, pp. 401-404, 1984.

[49] J. H. Cushman, G. D. Martinsen, and A. I. Mazeroll, "Densityand size-dependent spacing of ant nests: evidence for intraspecific competition," Oecologia, vol. 77, no. 4, pp. 522-525, 1988.

[50] L. Gallé, "Study of ant populations in various grassland ecosystems," Acta Biologica Szegediensis, vol. 18, pp. 159-164, 1972.

[51] K. Vepsäläinen and B. Pisarski, "Assembly of island ant communities," Annales Zoologici Fennici, vol. 19, no. 4, pp. 327-335, 1982.

[52] O. Alinvi, J. Bohlin, and J. P. Ball, "Interspecific competition among ants in the boreal forest: testing predictions from a linear hierarchical competition model," Insectes Sociaux, vol. 55, no. 1, pp. 1-11, 2008.

[53] K. Vepsäläinen and R. Savolainen, "The effect of interference by formicine ants on the foraging of Myrmica," Journal of Animal Ecology, vol. 59, no. 2, pp. 643-654, 1990. 
[54] N. Waloff and R. E. Blackith, "The growth and distribution of the mounds of Lasius flavus (Fabricius) (Hym: Formicidae) in Silwood Park, Bekshire," Journal of Animal Ecology, vol. 31, pp. 421-437, 1962.

[55] D. M. Gordon and A. W. Kulig, "Founding, foraging, and fighting: colony size and the spatial distribution of harvester ant nests," Ecology, vol. 77, no. 8, pp. 2393-2409, 1996.

[56] J. H. Fellers, "Daily and seasonal activity in woodland ants," Oecologia, vol. 78, no. 1, pp. 69-76, 1989.

[57] X. Cerdá, J. Retana, and A. Manzaneda, "The role of competition by dominants and temperature in the foraging of subordinate species in Mediterranean ant communities," Oecologia, vol. 117, no. 3, pp. 404-412, 1998.

[58] X. Cerdâ, J. Rctana, and S. Cros, "Prey size reverses the outcome of interference interactions of scavenger ants," Oikos, vol. 82, no. 1, pp. 99-110, 1998.

[59] M. Albrecht and N. J. Gotelli, "Spatial and temporal niche partitioning in grassland ants," Oecologia, vol. 126, no. 1, pp. 134141, 2001.

[60] J. F. A. Traniello, "Foraging strategies of ants," Annual Review of Entomology, vol. 34, pp. 191-210, 1989.

[61] I. Perfecto, "Foraging behavior as a determinant of asymmetric competitive interaction between two ant species in a tropical agroecosystem," Oecologia, vol. 98, no. 2, pp. 184-192, 1994.

[62] C. R. Carroll and D. H. Janzen, "Ecology of foraging by ants," Annual Review of Ecology and Systematics, vol. 4, pp. 231-257, 1973.

[63] J. F. A. Traniello, "Comparative foraging ecology of north temperate ants: the role of worker size and cooperative foraging in prey selection," Insectes Sociaux, vol. 34, no. 2, pp. 118-130, 1987.

[64] A. E. Chew and R. M. Chew, "Body size as a determinant of small-scale distributions of ants in evergreen woodland southeastern Arizona," Insectes Sociaux, vol. 27, no. 3, pp. 189-202, 1980.

[65] W. Czechowski and B. Markó, "Uncomfortable protection: Formica polyctena Först. shelters Formica fusca L. from Formica sanguinea Latr. (Hymenoptera: Formicidae)," Annales Zoologici, vol. 56, no. 3, pp. 539-548, 2006.

[66] J. Smallwood, "Nest relocations in ants," Insectes Sociaux, vol. 29, no. 2, pp. 138-147, 1982.

[67] D. M. Gordon, "Nest relocation in harvester ants," Annals of the Entomological Society of America, vol. 85, pp. 44-47, 1992.

[68] T. P. McGlynn, R. A. Carr, J. H. Carson, and J. Buma, "Frequent nest relocation in the ant Aphaenogaster araneoides: resources, competition, and natural enemies," Oikos, vol.106, no. 3, pp. 611621, 2004

[69] J. Frouz and V. Jilková, "The effect of ants on soil properties and processes (Hymenoptera: Formicidae)," Myrmecological News, vol. 11, pp. 191-199, 2008.

[70] C. J. Sanders, "The distribution of carpenter ant colonies in the spruce-fir forests of Northwestern Ontario," Ecology, vol. 51, no. 5, pp. 865-873, 1970 .

[71] Y. Chen, L. D. Hansen, and J. J. Brown, "Nesting sites of the carpenter ant, Camponotus vicinus (Mayr) (Hymenoptera: Formicidae) in Northern Idaho," Environmental Entomology, vol. 31, no. 6, pp. 1037-1042, 2002.

[72] W. Czechowski, A. Radchenko, W. Czechowska, and K. Vepsäläinen, The Ants of Poland with Reference to the Myrmecofauna of Europe, Museum and Institute of Zoology, Polish Academy of Sciences, Warszawa, Poland, 2012.
[73] L. Gallé, É. Kovács, and K. Margóczi, "Ants on trees: an example of metacommunities in extremely small patches," in Proceedings of the 7th European Ecological Congress, p. 85, Budapest, Hungary, 1995. 

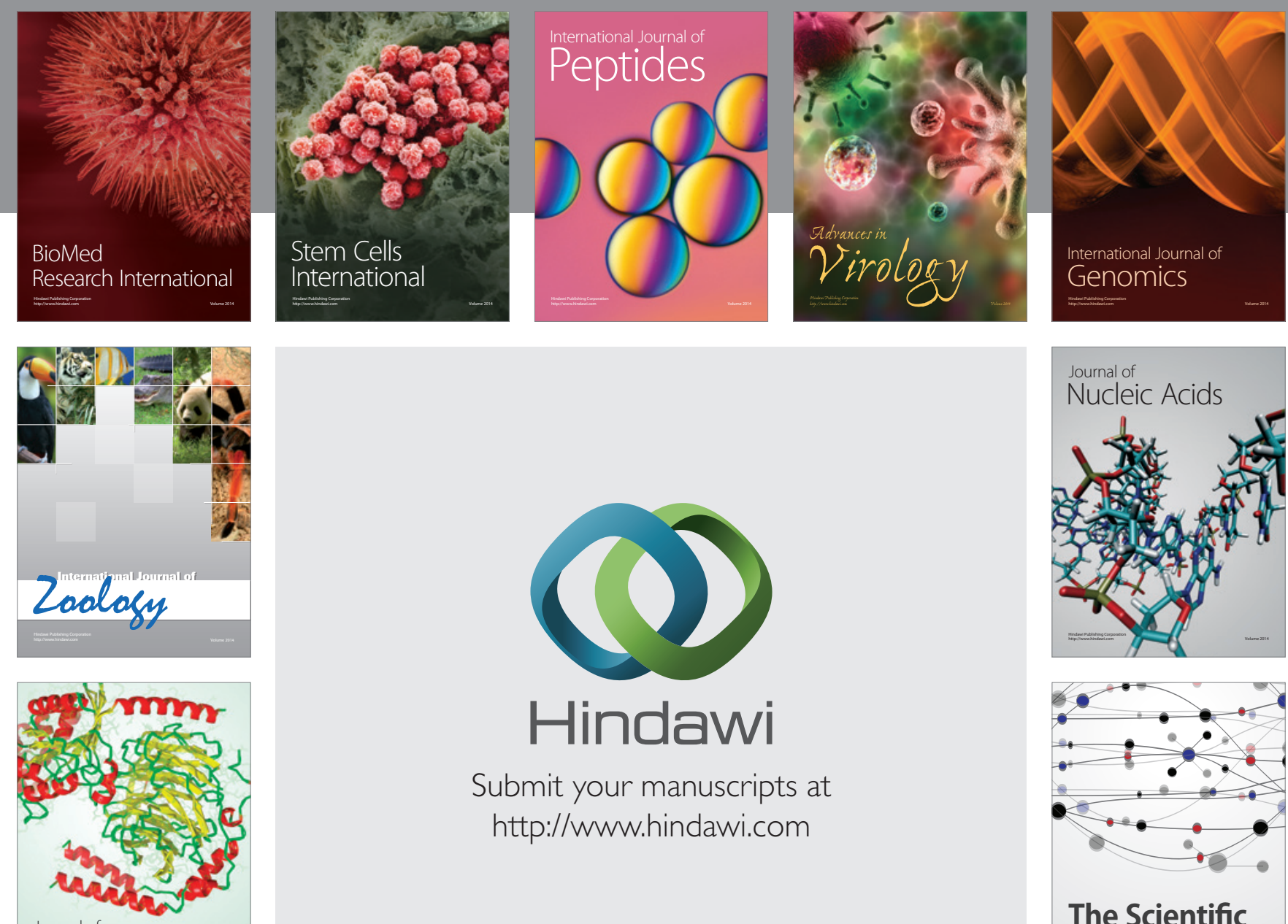

Submit your manuscripts at

http://www.hindawi.com

Journal of
Signal Transduction
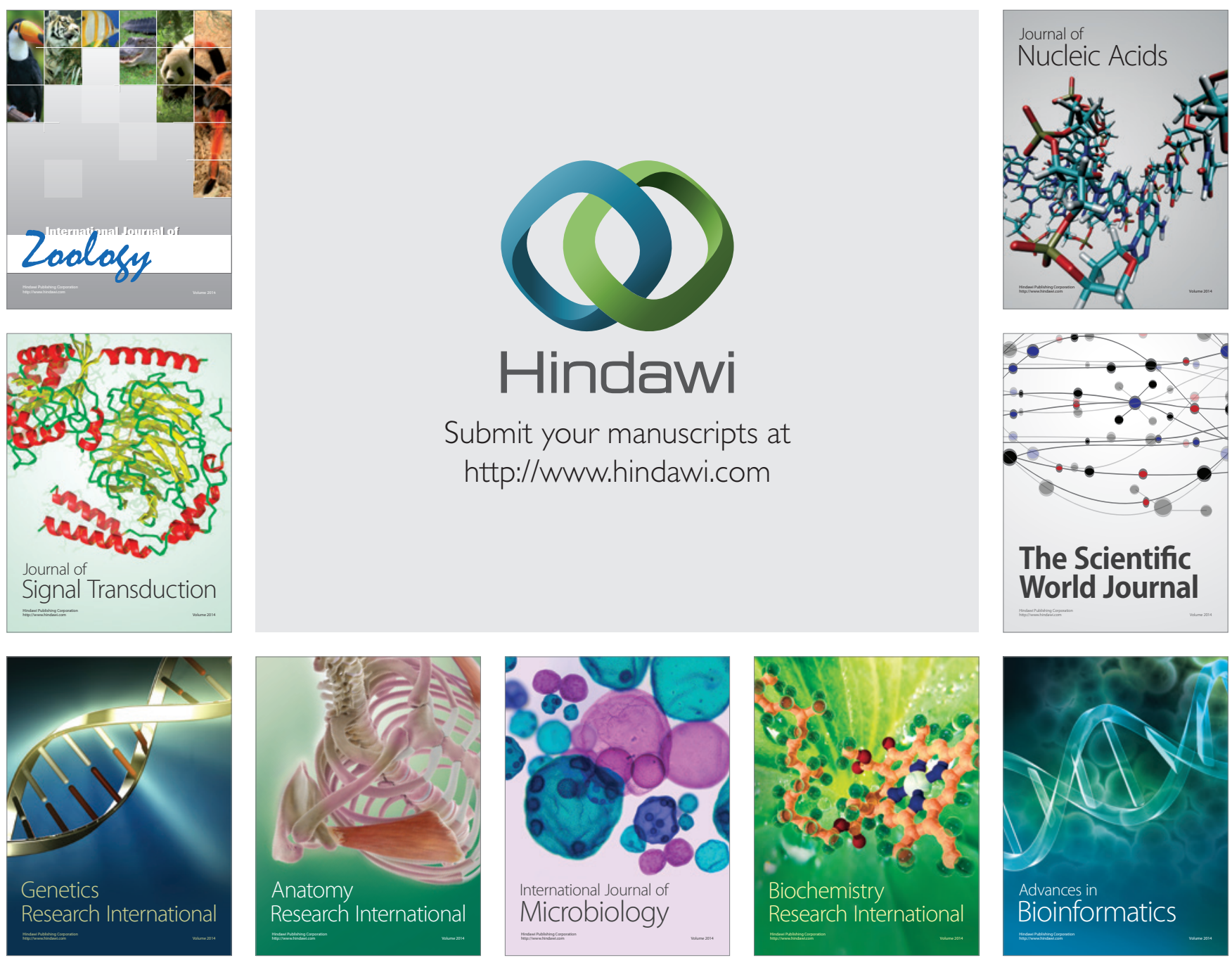

The Scientific World Journal
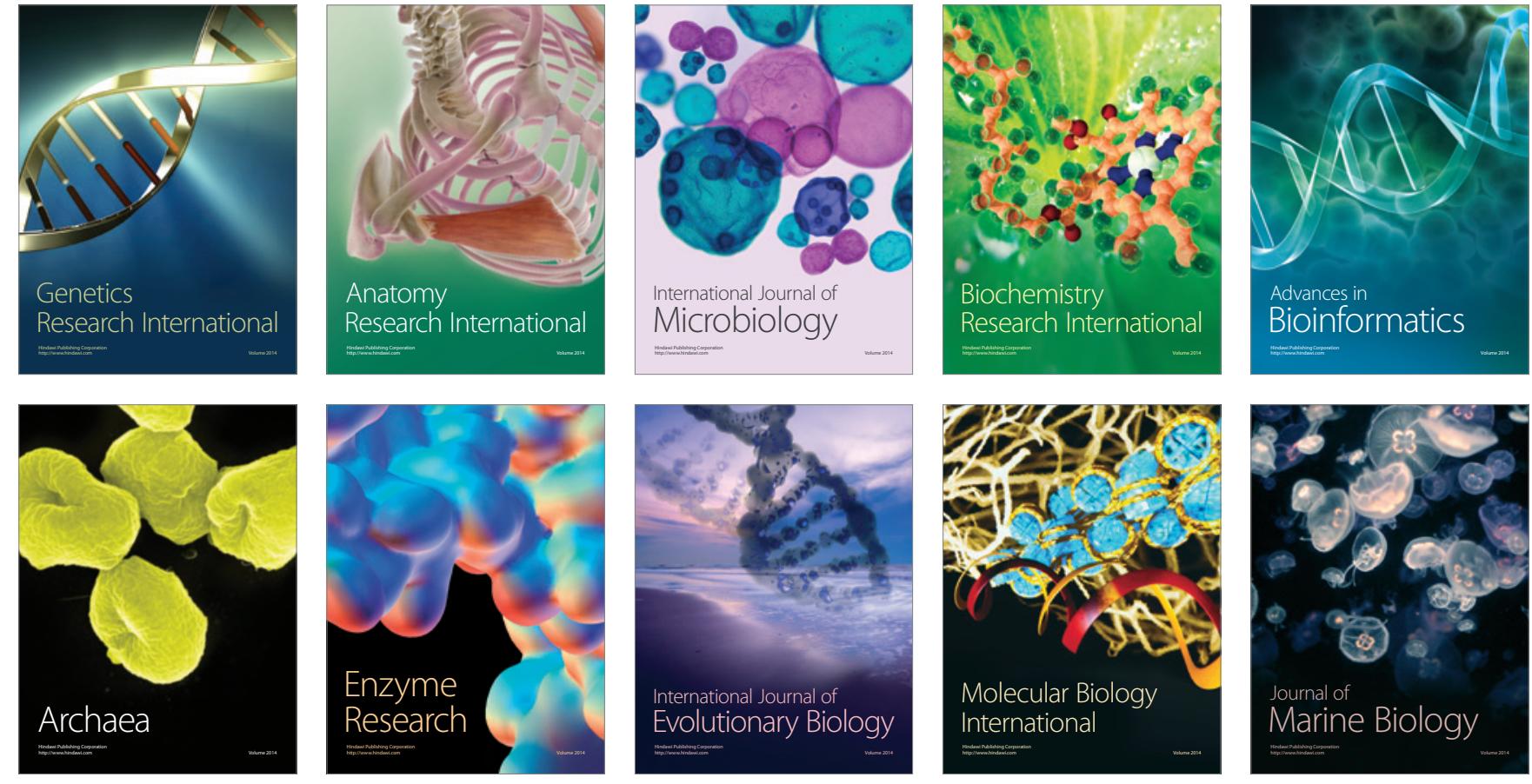